\title{
Laparoscopic entry technique-a survey of practices of consultant gynaecologists
}

Received: 19 June 2005 / Accepted: 11 August 2005/Published online: 31 August 2005

(C) Springer-Verlag Berlin / Heidelberg 2005

\begin{abstract}
To assess the mode of laparoscopic entry technique among consultant gynaecologists in the United Kingdom and Ireland and to find out whether recent recommendations have influenced practice, an anonymous postal questionnaire was sent to 1,190 gynaecologists. Responses were analysed using an Excel spreadsheet. There was a $64 \%$ response rate. Of the respondents, the majority $(90 \%)$ performed laparoscopy by using a Veress needle technique. Regarding the patient's position when inserting the scope, $61 \%$ used lithotomy with Trendelenberg tilt, and 39\% used the flat position. The entry point used was subumbilical by $54 \%$ and intraumbilical by $44 \%$. Thirty-eight percent used pressure and $62 \%$ used volume to decide when to insert the primary trocar. Only $26 \%$ of responding gynaecologists were aware of the Middlesbrough consensus document, but most who had attended a course were compliant with the guidelines. In conclusion, the majority of gynaecologists practiced closed laparoscopy and used the volume technique to achieve pneumoperitoneum. Only a small number of gynaecologists were aware of the recent recommendations regarding safe laparoscopic entry technique, suggesting that methods for disseminating recommendations must be improved.
\end{abstract}

Keywords Laparoscopic entry technique .

Closed laparoscopy $\cdot$ Recommendations

S. Lalchandani $(\bowtie)$

St Munchin's Regional Maternity Hospital, Ennis Road, Limerick, Republic of Ireland

E-mail: savitala15555@yahoo.com

Tel.: + 353-61-483148

Fax: + 353-61-482731

K. Phillips

Department of Obstetrics and Gynaecology,), Castle Hill Hospital, Castle Road, Cottingham, HU16 5JQ, East Yorkshire, UK

E-mail: Kevin.Phillips@hey.nhs.uk

Tel.: + 44-1482-875875

Fax: + 44-1482-624051

\section{Introduction}

Once relatively confined to obstetrics and gynaecology, laparoscopic procedures have exploded in the last decade. In the United States, 310,756 laparoscopic cholecystectomies were performed in 1997. Diagnostic laparoscopy was estimated to have been done in 91,170 cases, and laparoscopic sterilisation was estimated to have been done in 317,961 women [1]. The attraction of laparoscopy to the gynaecologist and general surgeon, as opposed to "open" operations, is the reduced trauma of access. Clear evidence shows that, compared with laparotomy, laparoscopic surgery provides significant benefits for patients, providers, and surgeons. Potential benefits for patients include reduced total operative trauma, fewer major wound and adhesive complications, quicker patient convalescence, and faster return to work or usual activities. The benefits for health care providers include shorter hospital stay with consequent lower hospital and social costs. The benefits for the surgeon include an almost closed and no-touch operative approach with reduced risk of infection, better display of anatomy and pathology, more precise removal of diseased tissue, and more accurate tissue repair [2-5].

However, as with any surgical procedure, the laparoscopic approach is associated with complications that must be offset against the expected clinical benefits. The larger medical and surgical community is still evaluating the safety and effectiveness of these laparoscopic procedures compared with traditional "open" surgical procedures [3, 6-8], although we know that the entry of the laparoscope into the abdomen is the most common cause of serious complications [9-11].

The umbilical area is the thinnest portion of the abdominal wall and is therefore the preferred access site [12]. However, immediately below this point are the aortic bifurcation, the bowel, and the omentum. Accessrelated injuries to these organs as well as to the inferior vena cava, liver, portal vein, cystic artery, ureter, 
bladder, iliac artery, and epigastric artery have all been reported $[12,13]$. Major vascular injuries are rare [14], but once they are inflicted, between $9 \%$ and $13 \%$ of patients will die, often as a consequence of haemorrhage or gas embolism $[15,16]$. Saber et al. carried out computed tomographic scan mapping of epigastric vessels and suggested that epigastric vessels are usually located in the area between 4 and $8 \mathrm{~cm}$ from the midline. They concluded that staying away from this area would determine the safety zone of entry of the anterior abdominal wall [17]. Access-related bowel or visceral injuries are more common. Reports indicate that between $50 \%$ and $66 \%$ of bowel and visceral injuries are undiagnosed at the time of primary surgery and can lead to major complications such as sepsis, peritonitis, and death [14].

Laparoscopic entry-related injuries can be classified into two main groups: type 1 injuries, which include damage by the Veress needle or trocar to normally located blood vessels and bowel, and type 2 injuries, which include damage by the Veress needle or trocar to bowel adherent to the abdominal wall. It is recognised that when bowel is firmly adherent to the anterior abdominal wall at the point of entry into the cavity, then bowel damage may occur, whether the mode of access is by laparotomy or laparoscopy (open or closed). Golan et al. carried out minilaparoscopy on women with history of previous multiple abdominal surgeries and concluded that minilaparoscopy performed with a 2-mm laparoscope inserted at the Palmer's point is safe and effective for identifying and preparing a proper cannula insertion point. This technique may be useful for avoiding bowel or other cannula-related trauma in women at high risk for such complications [18].

Despite the rapid evolution and adoption of laparoscopic surgery by general surgeons in the past decade, most case reports and large series reporting these injuries are derived from older gynaecologic literature. Even with newer instrumentation and knowledge, these injuries still occur frequently. In part, this may relate to a learning curve associated with adopting laparoscopic surgery, but additional factors include a lack of understanding of the mechanisms involved in creating these injuries and a lack of appreciation for the proximity of important visceral structures to the anterior abdominal wall.

Various recommendations have been published regarding safe laparoscopic entry techniques [19-24]. Garry and colleagues have formulated guidelines for closed and open laparoscopy, secondary ports, and proper patient selection and counselling, which could form a basis for safe practice $[19,22]$. The documented consensus has the support of the boards of the International Society of Gynaecological Endoscopy, the European Society of Gynaecological Endoscopy, the Australian Gynaecological Endoscopy Society, the British Society of Gynaecological Endoscopy, and the Minimal Access Surgery Training Group of the Royal
College of Obstetricians and Gynaecologists (RCOG). It is an authoritative document, although it is grade III evidence. The suggestions made include the following:

In closed laparoscopy, the primary incision should be made in the base of the umbilicus. If there is any suspicion of adhesions, an alternative entry choice is Palmer's point. Correct positioning of the needle should be checked by either Palmer's aspiration technique or observation of gas-flow pressure rates. The intraabdominal pressure should be $25 \mathrm{mmHg}$ at the time of trocar insertion, as this gives a large gas bubble, and with the tension of the anterior abdominal wall, the distance between the anterior abdominal wall and the intraabdominal organs is greatly increased and maintained during trocar insertion, which may reduce type I injuries. This theory is well supported by a Canadian study in which laparoscopy was performed in 259 women. The researchers looked at the volume of $\mathrm{CO}_{2}$ required to create a desired pressure and concluded that the mean $\mathrm{CO}_{2}$ volumes at $10,15,20$, and $25 \mathrm{mmHg}$ were $3.7,5.1,5.9$, and 6.51 , respectively. However, an adequate pneumoperitoneum is determined by $\mathrm{CO}_{2}$ insufflation to a pressure of $25 \mathrm{mmHg}$ and not by a preconceived volume of $\mathrm{CO}_{2}$ [22]. The primary trocar should be inserted through the thinnest part of the abdominal wall in the base of the umbilicus, and the laparoscope should be rotated $360^{\circ}$ to visually check for any evidence of adhesions, bowel damage, or haemorrhage. At the end of the procedure, the primary trocar should be removed under direct vision to exclude any previously unnoticed bowel lesions.

For open laparoscopy, there may be reduction or avoidance of type 1 lesions, but the chance of type 2 bowel lesions is not eliminated. To minimise the risk of such damage, the deep fascia should be elevated with suitable clamps to separate the abdominal wall from its contents after the placement of a skin incision at the lower border of the umbilicus. The fascial edges should be tagged with an adequate suture. The entry should be confirmed by visualising bowel or omentum before inserting the blunt-tipped cannula into the abdomen. At the end of the procedure, the fascial defect should be closed to minimise the risk of herniation.

Secondary trocars should be introduced under direct laparoscopic guidance to precisely control the depth and direction of their insertion.

Patient counselling plays an important role in reducing the risk of litigation. However, patients should be made aware that not all complications can be avoided. When counselling patients, clinicians should inform them of the following risks:

1. The possibility of injury to bowel, bladder, and blood vessels. This risk is in the range of 1-4 per 1,000 cases.

2. The possibility that conversion to laparotomy may be required and that on very rare occasions a temporary colostomy may be required. 
Patients and their doctors should expect a progressive and maintained improvement after laparoscopic surgery, and increasing pain or vomiting should alert them to the risk of a complication. The patient and family should leave the hospital with written information on how to recognise complications and what action to take in the event that they develop.

\section{Aim}

The aim of our survey was to assess the method of laparoscopic entry of consultant gynaecologists and to find out whether published recommendations have influenced routine practice.

\section{Methods}

An anonymous postal questionnaire was sent to all consultant gynaecologists in the United Kingdom and Ireland. The names and addresses of these consultants were obtained from RCOG, London. A total of 1,190 consultants were identified, and the questionnaire was sent in November 2002.

\section{Results}

The response rate was $64 \%(n=764)$ by April 2003. In view of the anonymous nature of the study, no followup of the nonresponders was undertaken. Among the 764 responding gynaecologists, one-third (264) were practicing in university or teaching hospitals. Six hundred and ninety $(90 \%)$ performed laparoscopy using a Veress needle, $56(8 \%)$ used a direct entry technique, nine $(1 \%)$ used Hasson's method, and nine $(1 \%)$ performed a combination of open and closed laparoscopy (Table 1).

Entry techniques used by responding gynaecologists

\begin{tabular}{ll}
\hline Entry technique & Total $=764$ \\
\hline Veress needle (closed) & $90 \%(690)$ \\
Direct entry & $8 \%(56)$ \\
Hasson's & $1 \%(9)$ \\
Combination & $1 \%(9)$ \\
\hline
\end{tabular}

The patient position used during both open and closed laparosopy was lithotomy with Trendelenberg tilt, used by $466(61 \%)$; flat, used by $222(29 \%)$; or a combination of positions, used by $76(10 \%)$.

The most common entry point, used by 414 (54\%) of the responding gynaecologists, was subumbilical, followed by intraubilical $(322 ; 42 \%)$ and suprapubic $(14 ; 2 \%)$, and $14(2 \%)$ used a combination of sites (Table 2).
Entry points used by responding gynaecologists

\begin{tabular}{ll}
\hline Entry point & Total $=764$ \\
\hline Subumbilical & $54 \%(414)$ \\
Intraumbilical & $44 \%(322)$ \\
Suprapubic & $2 \%(14)$ \\
Combination & $2 \%(14)$ \\
\hline
\end{tabular}

A check test, such as Palmer's aspiration technique, observation of gas flow rates and/or intraabdominal pressure rates, or abdominal tension for needle positioning, were not used by the majority $(431 ; 56 \%)$, whereas for the $333(44 \%)$ who did use one of the above tests, Palmer's aspiration test was the test of choice $(90 \%)$.

When respondents were asked whether they used volume or pressure for establishing pneumoperitoneum before trocar insertion, volume was used by the majority $(477 ; 62 \%)$; only $287(38 \%)$ used the intraabdominal pressure technique.

For those using a volume of gas to establish pneumoperitoneum before inserting the trocar, they quoted a wide range of volumes, from less than 2.0 to more than 3.51 (Table 3).

Volumes of gas used to create pneumoperitoneum

\begin{tabular}{ll}
\hline Volume (liters) & Total $=477$ \\
\hline 3.0 & $54 \%(258)$ \\
2.5 & $21 \%(100)$ \\
3.5 & $14 \%(67)$ \\
2.0 & $9 \%(42)$ \\
$<2.0$ or $>3.5$ & $2 \%(10)$ \\
\hline
\end{tabular}

For those using gas pressure to establish pneumoperitoneum prior to trocar insertion, the ranges quoted were anywhere between 15 and $25 \mathrm{mmHg}$ (Table 4).

Gas pressures used to create pneumoperitoneum

\begin{tabular}{ll}
\hline Pressure $(\mathrm{mmHg})$ & Total $=287$ \\
\hline 20 & $54 \%(122)$ \\
15 & $21 \%(93)$ \\
25 & $14 \%(46)$ \\
18 & $9 \%(11)$ \\
12 & $3 \%(10)$ \\
$<12$ & $2 \%(5)$ \\
\hline
\end{tabular}

When asked whether they would continue or change their techniques depending on a patient's previous history, $406(53 \%)$ gynaecologists said they would use the same technique irrespective of an individual's indication, whereas $358(47 \%)$ said they would change if the patient were obese or had a history of previous abdominal surgery. 
When asked whether they had changed their technique in the last 5 years, $263(34 \%)$ said they had done so.

When asked whether they had attended any minimal access surgery course recognised by RCOG or the British Society of Gynaecological Endoscopy (BSGE), only $257(34 \%)$ said they had attended one of the courses, whereas the majority $(507 ; 66 \%)$ had not been to any course. Of the gynaecologists who had attended a course, the majority $(177 ; 69 \%)$ were compliant with the guidelines, which indicates that it may be important for clinicians to attend a minimal access surgery course in order to achieve change (Table 5).

Compliance to guidelines by gynaecologists who had attended a minimal access surgery course recognised by the Royal College of Obstetricians and Gynaecologists or the British Society of Gynaecological Endoscopy

\begin{tabular}{ll}
\hline Compliant with guidelines & Total $=257$ \\
\hline Yes & $69 \%(177)$ \\
No & $31 \%(80)$ \\
\hline
\end{tabular}

When asked whether they were aware of any recent recommendations for safe laparoscopic entry technique, only $202(26 \%)$ said they had read some recommendations, whereas most $(562 ; 74 \%)$ were unaware of any such published documents.

\section{Discussion}

During the past two decades, rapid advances in laparoscopic surgery have made it an invaluable part of gynaecological and general surgical practice. A corresponding change in practice has occurred to encompass increasingly complex procedures, but there remains no clear consensus as to the optimal method of entry into the peritoneal cavity. More than half of all complications occur at the time of entry [23]; therefore, it is essential that entry technique be optimised. Many proponents of open and closed entry are found in the literature; some authors suggest, without sufficient collaborating evidence, that a particular method is superior and that they will continue to use their favoured technique [14, 24-29]. However, metaanalysis of all published data shows less bowel injury with the closed technique but benefits of the open technique in relation to vascular injury [3]. Jansen et al. [30] audited the practices of Dutch consultant gynaecologists to determine the incidence of complications of laparoscopy and their correlation with entry technique. In their study, which included more than 50,000 procedures, the number of entry-related visceral complications in the open technique was significantly higher than with the closed-entry technique. The researchers concluded that there was no evidence to abandon the closed-entry technique in laparoscopy. However, the selection of particular patients for an openor alternative-entry procedure was still recommended.
Our survey indicated that most gynaecologists practiced closed laparoscopy using a Veress needle. However, their patients were in the lithotomy position with a Trendelenberg tilt at the time of Veress entry, which theoretically would increase the risk of sustaining vascular injury by exposing the aortic bifurcation beneath the umbilicus, as the omentum and bowel fall away into the upper abdomen when in this position.

The majority inserted the Veress needle subumbilically, which is likely to increase the risk of preperitoneal gas insertion, especially in obese patients. Most used the volume of gas inserted for establishing pneumoperitoneum, but this does not allow a consistent space to be developed between the anterior abdominal wall and the intraabdominal organs because each patient's skin and fascia will vary in elasticity.

Only a third of the responding gynaecologists had attended an RCOG/BSGE-recognised minimal access surgery course, but even more concerning is that only a quarter were aware of any documents with recent recommendations on safe laparoscopic entry technique. Jones et al.[31] audited the implementation of a consensus guideline for safe laparoscopic entry technique and concluded that apart from laparoscopies performed on the professorial unit, a large number of procedures did not comply with the recommendations of the Middlesbrough consensus, leaving the question, "What is the best way to implement recommendations?"

Fortunately, complications are rare whatever the technique used, but this also means that gynaecologists doing a few laparoscopies each week may not encounter a complication for many years of practice, and hence they may be very reluctant to consider changing their practices. This situation is compounded by the paucity of randomised data to indicate which technique is the safest, but many of the expert groups' recommendations are based on study data, experience, and common sense. Hence, it may be difficult, if a complication occurs, to defend an individual who failed to recognise the existence of recommendations endorsed by expert groups. However, this paper does demonstrate that a wide range of techniques is still being used in gynaecological laparoscopic surgical practice in the UK and Ireland.

\section{Conclusion}

The laparoscopic approach is associated with complications that must be offset against the expected clinical benefits. This is the first survey to assess the method of laparoscopic entry of consultant gynaecologists and to find out whether published recommendations influence their routine practice. The aim of our survey was to audit the laparoscopic entry techniques of various consultant gynaecologists and, while by no means suggesting changing their techniques, hopefully to induce the thought, "Is the way I enter the abdomen with the laparoscope the safest it can be?" 
This survey shows that the majority of gynaecologists practice closed laparoscopy and use volume technique to achieve pneumoperitoneum, which is contrary to the recommendations. Only a small number of gynaecologists are aware of recent recommendations regarding safe laparoscopic entry technique. Most gynaecologists who have attended an RCOG/BSGE recognised course are compliant with guidelines, suggesting that attending a minimal access surgery course is important. To reduce the complications associated with entry technique, it is important to educate people and make them aware of the recent recommendations, but this may be difficult when complications rates are low, and for an individual clinician, his or her experience of a complication may be very rare. Unfortunately, the estimated number of laparoscopies that would need to be done in a randomised trial to demonstrate differences between the techniques has been estimated to be 80,000 patients per arm; therefore, such a trial is unlikely to be performed. But this does not imply that because the complication risk is low, no thought should be given to methods to reduce the risk further.

\section{References}

1. Agency for Healthcare Research and Quality. HCUPnet, Healthcare Cost and Utilization Project. http://www.ahrq.gov/ data/hcup/hcupnet.htm. 2001. Agency for Healthcare Research and Quality, Rockville, MD. Accessed 7-8-2001

2. Cuschieri A (1995) Whither minimal access surgery: tribulations and expectations. Am J Surg 169:9-19

3. Merlin T, Scott D, Rao M, Wall D, Francis D, Bridgewater F, Maddern G (2000) Systematic review of laparoscopic live donor nephrectomy - update and re-appraisal. ASERNIP-S Report No. 15, 2nd edn. ASERNIP-S, Adelaide, South Australia

4. Kerbl K, Clayman RV, McDougall EM, Gill IS, Wilson BS, Chandhoke PS, Albala DM, Kavoussi LR (1994) Transperitoneal nephrectomy for benign disease of the kidney-a comparison of laparoscopic and open surgical techniques. Urology 43(5):607-613

5. Parra RO, Perez MG, Boullier JA, Cummings JM (1995) Comparison between standard flanks versus laparoscopic nephrectomy for benign renal disease. J Urol 153:1171-1173

6. Lujan JA, Sanchez-Bueno F, Parilla P, Robles R, Torralba JA, Gonzalez-Costea R (1998) Laparoscopic vs. open cholecystectomy in patients aged 65 and older. Surg Laparosc Endosc 8(3):208-210

7. Ortega AE, Hunter JG, Peters JH, Swanstrom LL, Schirmer B (1995) A prospective, randomized comparison of laparoscopic appendectomy with open appendectomy. Laparoscopic appendectomy study group. Am J Surg 169(2):208-212

8. Picchio M, Lombardi A, Zolovkins A, Mihelsons M, La Torre G (1999) Tension-free laparoscopic and open hernia repair: randomised controlled trial of early results. World J Surg 23(10):1004-1007

9. Leron E, Piura B, Ohana E, Mazor M (1998) Delayed recognition of major vascular injury during laparoscopy. Eur J Obstet Gynaecol Reprod Biol 79(1):91-93

10. Nuzzo G, Giuliante F, Tebala GD, Vellone M, Cavicchioni C (1997) Routine use of open technique in laparoscopic operations. J Am Coll Surg 184:58-62
11. Riedel HH, Lehmann WE, Mecke H, Semm K (1989) The frequency distribution of various pelviscopic (laparoscopic) operations, including complication rates - statistics of the Federal Republic of Germany in the years 1983-1985. Zentralblatt Gynakologie 111(2):78-91

12. Airan MC (1996) Basic techniques. In: McFadyen BV, Ponsky JL (eds) Operative laparoscopy and thoracoscopy. LippincottRaven, Philadelphia, pp 93-123

13. Lin P, Grow DR (1999) Complications of laparoscopy - strategies for prevention and cure. Obstet Gynaecol Clin North Am 26:23

14. Rosen DM, Lam AM, Chapman M, Carlton M, Cario GM (1998) Methods of creating pneumoperitoneum: a review of techniques and complications. Obstet Gynaecol Surv 53:167174

15. Deziel DJ, Millikan KW, Economou SG, Doolas A, Ko S, Airan MC (1993) Complications of laparoscopic cholecystectomy: a national survey of 4,292 hospitals and an analysis of 77,604 cases. Am J Surg 165:9-14

16. Baadsgaard SE, Bille S, Egeblad K (1989) Major vascular injury during gynecologic laparoscopy. Report of a case and review of published cases. Acta Obstet Gynecol Scand 68(3):283-285

17. Saber AA, Meslemani AM, Davis R, Pimentel R (2004) Safety zones for anterior abdominal wall entry during laparoscopy: a CT scan mapping of epigastric vessels. Ann Surg 239(2):182185

18. Golan A, Sagiv R, Debby A, Glezerman M (2003) The minilaparoscope as a tool for localization and preparation for cannula insertion in patients with multiple previous abdominal incisions or umbilical hernia. J Am Assoc Gynaecol Laparosc 10(1):14-16

19. Garry R (1999) A consensus document concerning laparoscopic entry techniques: Middlesbrough, March 19-20 1999. Gynaecol Endosc 8:403-406

20. Ewen S (1999) Avoiding complications of the laparoscopic approach. Obstet Gynaecol 1(1):34-36

21. Kalu G, Wright J (2001) Laparoscopic surgery and the law. Obstet Gynaecol 3(3):141-146

22. Vilos GA, Vilos AG (2003) Safe laparoscopic entry guided by Veress needle $\mathrm{CO}_{2}$ insufflation pressure. J Am Assoc Gynaecol Laparose 10(3):415-420

23. Jansen FW, Kapiteyn K, Trimboskemper T, Hermans J, Trimbos JB (1997) Complications of laparoscopy: a prospective multicentre observational study. $\mathrm{Br} \mathrm{J}$ Obstet Gynaecol 104:595-600

24. Garry R (1999) Towards evidence-based laparoscopic entry techniques: clinical problems and dilemmas. Gynaecol Endosc 8:403-406

25. O'Callaghan D, Maher PJ, Hill DJ (1996) Complications of closed laparoscopy: is the Veress needle safe? Aust N Z J Surg 66(8):505-507

26. Pickersgill A, Slade RJ, Falconer GF, Attwood S (1999) Open laparoscopy: the way forward. Br J Obstet Gynaecol 106:11161119

27. Hasson H (1999) Open laparoscopy as a method of access in laparoscopic surgery. Gynaecol Endosc 8:353

28. Saidi MH (1986) Direct laparoscopy without prior pneumoperitoneum. J Reprod Med 31(8):684-686

29. Kaloo P, Cooper M, Reid G (2002) A prospective multicentre study of laparoscopic complications related to the direct-entry technique. Gynaecol Endosc 11:67-70

30. Jansen FW, Kolkman W, Bakkum EA, de Kroon CD, Trimbos-Kemper TC, Trimbos JB (2004) Complications of laparoscopy: an inquiry about closed- versus open-entry technique. Am J Obstet Gynaec 190(3):634-638

31. Jones K, Fan A, Sutton C (2002) Safe entry during laparoscopy: a prospective audit in a district general hospital. Gynaecol Endosc 11:85-89 